\title{
The influence of inherent properties of building limestones on their bioreceptivity to phototrophic microorganisms
}

\author{
Ana Zélia MILLER ${ }^{1,2 *}$, Amélia DIONÍSIO², Leonila LAIZ³ ${ }^{3}$ Maria Filomena MACEDOํㅜ, Cesareo SAIZ-JIMENEZ ${ }^{3}$ \\ ${ }_{1}^{1}$ Departamento de Conservação e Restauro, Faculdade de Ciências e Tecnologia, Universidade Nova de Lisboa, Monte da \\ Caparica, 2829-516 Caparica, Portugal; ${ }^{2}$ Centro de Petrologia e Geoquímica, Departamento de Engenharia de Minas e \\ Georrecursos, Instituto Superior Técnico, Av. Rovisco Pais, 1049-001 Lisboa, Portugal; ${ }^{3}$ Instituto de Recursos Naturales y \\ Agrobiologia, CSIC, Apartado 1052, 41080 Sevilla, Spain
}

Received 21 July 2009 / Accepted 12 October 2009

\begin{abstract}
The influence of open porosity, water absorption capillarity, water vapour permeability, surface roughness, stone $\mathrm{pH}$ and chemical composition on stone bioreceptivity to phototrophic microorganisms was assessed by means of a thorough stone characterisation with subsequent artificially inoculation of limestone samples with a multi-species phototrophic culture and placing them inside a growth chamber for 90 days. A principal component analysis and an analysis of variance (ANOVA) were carried out in order to evaluate the direct relationships between stone bioreceptivity and petrophysical properties. From the principal component analysis, two main components were obtained and assigned a petrophysical/photosynthetic biomass meaning. Stone bioreceptivity, quantified by the amount of chlorophyll $a$ and intensity of chlorophyll a fluorescence present on the stone samples after 90 days-incubation, was included in both principal components. The first component was linked to the amount of chlorophyll $a$ and was highly and linearly associated to capillarity and roughness, and less associated with open porosity and water vapour permeability. The second component, linked to the intensity of chlorophyll a fluorescence measured on the stone surfaces, was not linearly associated with the petrophysycal properties, showing the fallibility of this in vivo chlorophyll quantification technique on the estimation of photosynthetic biomass growing on stone materials, particularly when endolithic growth occurs.
\end{abstract}

Key words: limestone; petrophysical properties; porosity; permeability; chlorophyll a.

\section{INTRODUCTION}

Linking the bioreceptivity of building materials to their petrophysical and petrochemical properties, including water flow, surface roughness and texture, and mineralogical composition, has generated great interest in the fields of conservation sciences, biodeterioration, architecture and earth sciences. Bioreceptivity is connected with the susceptibility of a material to be colonised by one or several groups of organisms (Guillitte, 1995). A number of factors influence biological colonisation on porous materials, including i) intrinsic properties of the stone material, such as porosity, roughness and permeability that strongly influence water availability for microorganisms; ii) environmental parameters (e.g. solar radiation, temperature, water regime, climate, etc.); iii) specific microclimatic parameters (e.g. orientation, exposure to shadow, permanent capillary humidity, etc.).

In order to assess the bioreceptivity of building stones, artificial colonisation experiments comprising the inoculation of stones with single species or few isolated strains under laboratory condi-

\footnotetext{
* Corresponding Author. Phone/Fax: +351 2129483 22;

E-mail: azm@fct.unl.pt
}

tions have been developed (Guillitte and Dreesen, 1995; Tiano et al., 1995; Shirakawa et al., 2003; Prieto and Silva, 2005; Miller et al., 2006). However, these studies are only indications, as many types of stone colonisation are part of complex structural and functional ecosystems. Microorganisms on exposed stone surfaces rarely grow as colonies comprising a single species; rather they form communities that derive their survival and success from a collective growth microhabitat, known as biofilm. These biofilms are formed at the interface between the atmosphere and the lithic substratum by microorganisms enclosed in a hydrated polysaccharide matrix (Costerton et al., 1995; Gorbushina, 2007). Biofilms formed on the stones exposed to environmental conditions are dominated by associations of algae, cyanobacteria, fungi and heterotrophic bacteria, which cause fouling problems through their growth on the substrata. Many environmental factors influence the settlement, growth and development of these microorganisms on stone surfaces since they are subjected to fluctuations of temperature, humidity, solar radiation, lack of nutrients, etc. Nevertheless, stone surface biofilms constitute a protected mode of growth that allows survival in hostile environments, as well as resistance to biocides and ultraviolet radiation (Prakash et al., 2003). The metabolic activity of biofilms centre on retention of water, protecting the cells from fluctuating envi- 
ronmental conditions and solar radiation as well as prolonging their vegetative life (Gorbushina, 2007).

Hence, not all the organisms present on exposed stone surfaces can develop on artificial conditions, even if very close to those present in nature. Moreover, tests made with a single organism can become either impossible or completely atypical. In fact, the results reported in laboratory-based colonisation experiments can be considered pertinent only for the stones used, the organisms tested and the incubation conditions applied. Nevertheless, these studies not only assessed the stone bioreceptivity but also the biofilm distribution, damages caused by the tested organisms and the relationships between microorganisms and stone substrata, demonstrating that biological colonisation depends on the stone properties in addition to environmental conditions.

For the quantification of cyanobacterial and algal biomass developing on stone monuments, in vitro and in vivo chlorophyll a estimation methods have been applied (Cecchi et al., 2000; Bellinzoni et al., 2003; Prieto and Silva, 2005; Miller et al., 2006). In vitro chlorophyll a technique is based on the extraction of chlorophyll $a$ in an organic solvent with subsequent determination by spectrophotometry. This technique is one of the best methods for the quantification of photosynthetic biomass in aquatic and terrestrial ecosystems. However, one of the disadvantages inherent to this method is the scaffolding and sampling procedure required, which becomes more relevant when samples are collected from cultural heritage assets (thus a limitation in their number). In recent years, the measurements of in vivo chlorophyll fluorescence were introduced in the analysis to detect phototrophic organisms dwelling on stone monuments as a rapid, reliable and non-destructive technique for chlorophyl a estimation (Cecchi et al., 2000; Tomaselli et al., 2002; Miller et al., 2006). Fluorescence is one of the key characteristics of chlorophyll $a$. Spectrofluorometry with fibre-optic platform allows measurements of in vivo chlorophyll a fluorescence on solid substrata without sampling procedures.

In this paper, principal component analysis was applied to assess direct relationships between biological colonisation by phototrophic microorganisms and some intrinsic properties of five different building limestones. To achieve this aim a multidisciplinary team operated to conduct the bioreceptivity parameters measurements either for quantify phototrophic biomass or to characterise the stone materials. The efficacy of in vitro and in vivo phototrophic biomass estimation methods was also compared.

\section{MATERIALS AND METHODS}

Limestone samples. Five types of natural porous stones were selected for their importance as building materials in the monumental architecture of Mediterranean Basin European countries. Fresh cut quarry limestone samples corresponding to five types of sedimentary rocks with different intrinsic characteristics were studied:

Ançã limestone (CA): light whitish-yellow fine-grained compact and homogeneous limestone belonging to the Jurassic Ançã limestone formation (Coimbra, Portugal). The stone is bioclastic and calciclastic, showing oolitic tendency and containing spathised micritic cement. The mineralogical composition is predominately calcitic with a $\mathrm{CaCO}_{3}$ relative weight proportion higher than $96.5 \%$.

Lioz limestone $(\mathrm{CL})$ : beige-rosy microcrystalline limestone, calciclastic and bioclastic, abundantly fossiliferous from the middle Crestaceous. It is a traditional ornamental Portuguese limestone, quarried in the North region of Lisbon (Pero Pinheiro). Calcite is the main component of the stone.

San Cristobal stone (SC): yellowish medium-grained bioclastic calcarenite of the upper Miocene widely used in historic buildings from Seville and Cadiz provinces (Spain) and is quarried in El Puerto de Santa Maria (Cadiz). Calcite is the principal constituent with quartz grains less than $50 \%$. It exhibits an inequigranular heterogeneous texture, with very scarce matrix and low cementation level.

Escúzar stone (PF): light-coloured fine-to-medium grained biocalcarenite from the Tortonian age, widely used in monuments from Granada (Southern Spain). It is quarried in Santa Pudia area (Escúzar, Spain). The limestone tested is a highly porous stone with a microsparitic matrix evidencing a second generation of sparitic carbonate cement containing a great variety of bioclasts (Rodriguez-Navarro and Sebastian, 1996).

Lecce stone (PL): Miocene limestone of biological origin, quarried in the Lecce province (Salentine Peninsula, Italy). The stone, dark yellow in colour, is homogeneous and fine grained, composed by sparite bioclasts included in a very fine micrite matrix, presenting low cementation level.

A detailed petrographic characterisation of the five lithotypes has been provided by Miller et al. (2010).

Characterisation of limestone samples. In order to study the influence of the selected lithotypes on the growth of phototrophic microorganisms, intrinsic properties of each substratum were characterised.

Petrophysical characteristics were analysed in terms of water vapour permeability, surface roughness, open porosity and water absorption capillarity. Water vapour permeability measurements have been carried out using sample cells according to the wet cup ASTM E96/E96M - 05 (2005) standard method and Normal $21 / 85$ (1985). Containers, with a known volume of water, closed by a sample of $1 \mathrm{~cm}$ in thickness were used. The containers were submitted to a controlled temperature of $20 \pm 2{ }^{\circ} \mathrm{C}$ in an environment of $40 \pm 5 \%$ relative humidity inside a climatic chamber (Fitoclima ${ }^{\circledR}$, Aralab). The containers were weighed at suitable time intervals until the weight stabilised, when mass differences were less than $5 \%$. The water vapour transmission rate is determined by the change in mass at the steady state of the system. The results are expressed as water vapour permeability in $\mathrm{kg}$ $\mathrm{m}^{-1} \mathrm{~s}^{-1} \mathrm{~Pa}^{-1}$.

The surface roughness of the five stone materials was assessed using an optical surface roughness instrument (TRACEIT $尺)$ and parameters like Ra $(\mu \mathrm{m})$, the arithmetic mean of the absolute values of the roughness profile ordinates, and Rz $(\mu \mathrm{m})$, arithmetic mean value of the single roughness depths (the vertical distance between the highest peak and the deepest valley within a sampling length) of five consecutive sampling lengths were evaluated. A standard area of $5 \times 5 \mathrm{~mm}$ was used for each measurement and four sampling areas were used for each stone sample. This instrument also allowed the establishment of 3D micro-topography of the stone samples.

Hygric properties, such as open porosity and water absorption capillarity were accomplished on 27 samples of each lithotype according to European Standards EN 1936:1999 (1999) and EN 1925:1999 (1999), respectively.

Stone suspension $\mathrm{pH}$ values were also determined using a Eutech Instruments digital pH meter after grinding $20 \mathrm{~g}$ of stone with $2 \mathrm{~mm}$ grain-size and adding in $100 \mathrm{~mL}$ of distilled water, which was mixed and allowed to settle.

The chemical composition of the selected lithotypes was determined at Instituto Superior Técnico, Laboratório de Mineralogia e 
Petrologia (Portugal), using the following methods: atomic absorption spectrometry for $\mathrm{Ca}, \mathrm{Mg}, \mathrm{Mn}$; emission spectrometry for $\mathrm{Na}, \mathrm{K}$; colorimetric methods for $\mathrm{Al}, \mathrm{Fe}$ total and $\mathrm{SiO}_{2}$. The loss on ignition (LOI) was determined by weighing the powdered samples $(1 \mathrm{~g}$ ) both before and after being heated at $1000{ }^{\circ} \mathrm{C}$ for $5 \mathrm{~h}$.

Tested microorganisms and stone inoculation. There is general agreement within the scientific community that in nature microorganisms involved in stone biofouling develop in more or less complex communities because of the diversity of rock ecosystems. Consequently, the choice should comprise those organisms that are potential deteriorating agents of the selected stone materials. In order to select a multi-species community culture stable under laboratory conditions for further artificial inoculation of the lithotypes, different photosynthetic-based biofilms were collected from limestone monuments, characterised and cultivated in a previous work (Miller et al., 2010). One phototrophic culture with remarkable stability under laboratory conditions of the microbial components within the natural biofilm sample was obtained. The major components of the inoculum were Chlorella, Stichococcus, Trebouxia and Myrmecia, among the Chlorophyta, and Leptolyngbya and Pleurocapsa among the Cyanobacteria.

The artificial colonisation experiment was performed by inoculating the upper surface of 21 sterilised cylinder samples (4.4 cm diameter and $2 \mathrm{~cm}$ height) of each lithotype with 0.75 $\mathrm{mL}$ of the selected multi-species phototrophic culture. Before the inoculation of the stone samples was initiated, the concentration of chlorophyll $a$ of the culture at the inoculation time $\left(2.9 \mathrm{~g} \mathrm{~L}^{-1}\right)$ was measured by extracting chlorophyll in dimethyl-sulfoxide (DMSO) (Shoaf and Lium, 1976) with subsequent determination by spectrophotometry, as described by Burnison (1980). After inoculation, the stone samples were placed in a non-commercial climatic chamber at $20 \pm 2{ }^{\circ} \mathrm{C}$ under $12 \mathrm{~h}$ dark/light (1200 lux) cycles during 90 days. Moisture inside the chamber was maintained by periodically adding of sterilised water to the bottom of the chamber.

Quantification of phototrophic growth on the limestone samples. For the assessment of the phototrophic growth on the stone samples during the 90 days of incubation, two different phototrophic biomass estimation methods were applied and compared.

Stone samples of each lithotype were taken in triplicate for the extraction of chlorophyll $a$ after 30, 60 and 90 days of incubation. The amounts of chlorophyll a extracted from each stone sample were determined according to the pigment extraction protocol for periphyton (Vollenweider et al., 1974). The extractions were performed by crushing each colonised stone sample ( 20-50 $\mathrm{mm}^{3}$ fragments), which were added to $50 \mathrm{~mL}$ of DMSO and heated at $65^{\circ} \mathrm{C}$ for $1 \mathrm{~h}$. The absorbances of the extracts at 665 and $750 \mathrm{~nm}$, before and after acidification with $1 \mathrm{~N} \mathrm{HCl}$, were measured in a spectrophotometer after filtration of the samples to remove stone particles. The Lorenzen (1967) equations were used to calculate chlorophyll a concentrations, using the absorption coefficient from Talling and Driver (1963).

The growth of phototrophic communities on the selected stone materials was also assessed by the in vivo chlorophyll a fluorescence method, using a spectrofluorometer (Fluorolog-3 FL3-22) fitted with a fibre-optic platform (Horiba Jobin Yvon $\mathrm{F}-3000$ ). This is a very fast, safe and easy method to apply for the estimation of phototrophic biofilms dwelling on stone materials. Stone samples of each lithotype were taken out of the chamber in triplicate at the inoculation time and after each 30 days of incubation (0, 30, 60 and 90 days). For each stone sample five spectrofluorometric measurements were randomly carried out on the surface covered area. It was used an excitation wavelength of $430 \mathrm{~nm}$, slits of $4.5 \mathrm{~nm}$, an integration time of $0.3 \mathrm{~s}$ and an increment of $1.0 \mathrm{~nm}$.

Statistical analysis. In order to relate the intrinsic parameters that influence the stone colonisation by phototrophic microorganisms and to estimate the efficacy of both chlorophyll a quantification methods, the experimental data were subject to analysis of variance (ANOVA) using Statistica 7.0 software for Windows, and the averages were compared by the Tukey HDS Test at the $5 \%$ level of significance.

A principal component analysis (PCA) was also performed in order to establish the structure of the variable dependence. This involves identifying relationships between variables and in assigning a petrophysical/photosynthetic biomass meaning to each factor.

\section{RESULTS}

\section{Limestone characteristics}

The physical parameters values attained for the five tested lithotypes showed a great array of values, which included very high porosities, such as the Lecce (PL) and Escúzar (PF) stones, contrasting with the very low porosity of Lioz limestone $(\mathrm{CL})$. Petrophysical characteristics of the various lithotypes are summarised in Table 1 . The high open porosity values obtained for Ançã limestone (19\%), San Cristobal stone (28\%), Escúzar stone (33\%) and Lecce stone (43\%) contrasted with the very low open porosity of $L i o z$ limestone $(0.5 \%)$. A similar pattern was obtained for their capillarity coefficients (Table 1 ), showing that all lithotypes took up water more rapidly than the CL.

The water vapour permeability, which is the ability of the vapour under pressure to flow on porous media, displayed the lowest value for $\mathrm{CL}$ (Table 1). In contrast, PL and PF exhibited the highest permeability values, followed by $\mathrm{CL}$ and SC (San Cristobal stone). These values are indicative of a relative high ability of these lithotypes to fluids circulation on its porous media. Lowest mean values for water vapour permeability, open porosity and capillary coefficient were recorded for $\mathrm{CL}$.

The studied lithotypes included either stones with very low roughness, namely $C A$ and $C L$, or with considerable roughness values, i.e. SC lithotype (Table 1 and Fig. 1). Rz values were approximately 3.7-5.30 times higher than Ra values. It must be mentioned that all stone samples were prepared using a diamond swan, and thus the measured roughness is the result of combined action of stone factors that occurred during the swan process.

The measured values of the stone suspension $\mathrm{pH}$ did not vary greatly among the tested stones; they are basic $\mathrm{pH}$ stones. ANOVA revealed a significant difference $(p<0.05)$ in the stone suspension $\mathrm{pH}$ of the PL lithotype. The samples of CA, PF, CL and SC were not significantly different (Table 1 ).

The chemical composition of the five lithotypes is strictly related to the mineralogical composition of each type of stone. Representative data of the main chemical composition of these lithotypes are presented in Table 2. The five lithotypes are calcitic carbonates with a $\mathrm{CaO}$ concentration varying between 33.72 and $55.23 \%$. SC presented the highest concentration of $\mathrm{SiO}_{2}$ $(38.45 \%)$, confirming the presence of quartz clasts as described by Miller et al. (2010) and $\mathrm{Fe}_{2} \mathrm{O}_{3}(0.41 \%)$. The lowest concentrations in $\mathrm{CaO}(33.72 \%), \mathrm{Na}_{2} \mathrm{O}(0.12 \%), \mathrm{K}_{2} \mathrm{O}(0.05 \%)$ were also displayed by this lithotype. PF is a biocalcarenite in which only 
TABLE 1 - ANOVA results obtained for the physic parameters analysed in this work: open porosity and capillary absorption coefficient (from Miller et al. 2010), water vapour permeability, surface roughness (Ra and Rz) and stone suspension $\mathrm{pH}$.

\begin{tabular}{lcccccc}
\hline Lithotype & $\begin{array}{c}\text { Open porosity } \\
(\%)\end{array}$ & $\begin{array}{c}\text { Capillary coefficient } \\
\left(\mathrm{g} \cdot \mathrm{m}^{-2} \cdot \mathrm{s}^{-1 / 2}\right)\end{array}$ & $\begin{array}{c}\text { Water vapour permeability } \\
\left(\mathrm{kg} \cdot \mathrm{m}^{-1} \cdot \mathrm{s}^{-1} \cdot \mathrm{Pa}\right)\end{array}$ & $\begin{array}{c}\mathrm{Ra} \\
(\mu \mathrm{m})\end{array}$ & $\begin{array}{c}\text { Rz } \\
(\mu \mathrm{m})\end{array}$ & $\begin{array}{c}\text { Stone suspen- } \\
\text { sion }(\mathrm{pH})\end{array}$ \\
\hline $\begin{array}{l}\text { Ançã limestone } \\
(\mathrm{CA})\end{array}$ & $18.95 \pm 0.27$ & $57.25 \pm 1.17$ & $7.04 \times 10^{-12} \pm 3.53 \times 10^{-13} \mathrm{c}$ & $1.61 \pm 0.40 \mathrm{~b}$ & $8.52 \pm 1.90 \mathrm{~b}$ & $8.52 \pm 0.04 \mathrm{~d}$ \\
$\begin{array}{l}\text { Lioz limestone } \\
(\mathrm{CL})\end{array}$ & $0.53 \pm 0.06$ & $0.20 \pm 0.06$ & $8.18 \times 10^{-13} \pm 1.95 \times 10^{-13}$ & $1.59 \pm 0.42 \mathrm{a}$ & $7.99 \pm 1.92 \mathrm{a}$ & $8.61 \pm 0.02 \mathrm{~cd}$ \\
$\begin{array}{l}\text { San Cristobal } \\
\text { stone (SC) }\end{array}$ & $28.07 \pm 1.88$ & $199.30 \pm 31.05$ & $4.54 \times 10^{-12} \pm 2.12 \times 10^{-12} \mathrm{a}$ & $8.16 \pm 2.16 \mathrm{de}$ & $30.56 \pm 10.56 \mathrm{de}$ & $8.67 \pm 0.03 \mathrm{~b}$ \\
$\begin{array}{l}\text { Escúzar stone } \\
\text { (PF) }\end{array}$ & $32.92 \pm 0.97$ & $268.79 \pm 77.54$ & $1.08 \times 10^{-11} \pm 9.51 \times 10^{-13} \mathrm{e}$ & $5.98 \pm 1.28 \mathrm{ce}$ & $24.99 \pm 5.07 \mathrm{ce}$ & $8.57 \pm 0.02 \mathrm{ab}$ \\
Lecce stone (PL) & $43.24 \pm 0.68$ & $128.76 \pm 3.04$ & $1.09 \times 10^{-11} \pm 5.19 \times 10^{-13} \mathrm{~d}$ & $6.14 \pm 0.63 \mathrm{~cd}$ & $27.67 \pm 2.64 \mathrm{~cd}$ & $8.41 \pm 0.03$ \\
\hline
\end{tabular}

The values correspond to average \pm SD. Average followed by the same letters in a column are not significantly different by the Tukey HDS test at $p<0.05$.

carbonate materials seem to be present and, thus, its content of $\mathrm{SiO}_{2}$ is low $(1.19 \%)$. PL exhibited the highest $\mathrm{Al}_{2} \mathrm{O}_{3}$, which is related with its composition on clay minerals (ranging from 3 to
$12 \%$ ) (Miller et al., 2010). On the basis of $\mathrm{Ca} / \mathrm{Mg}$ (weight) ratios (Chilingar et al., 1967), the studied lithotypes are classified as calcitic limestones.
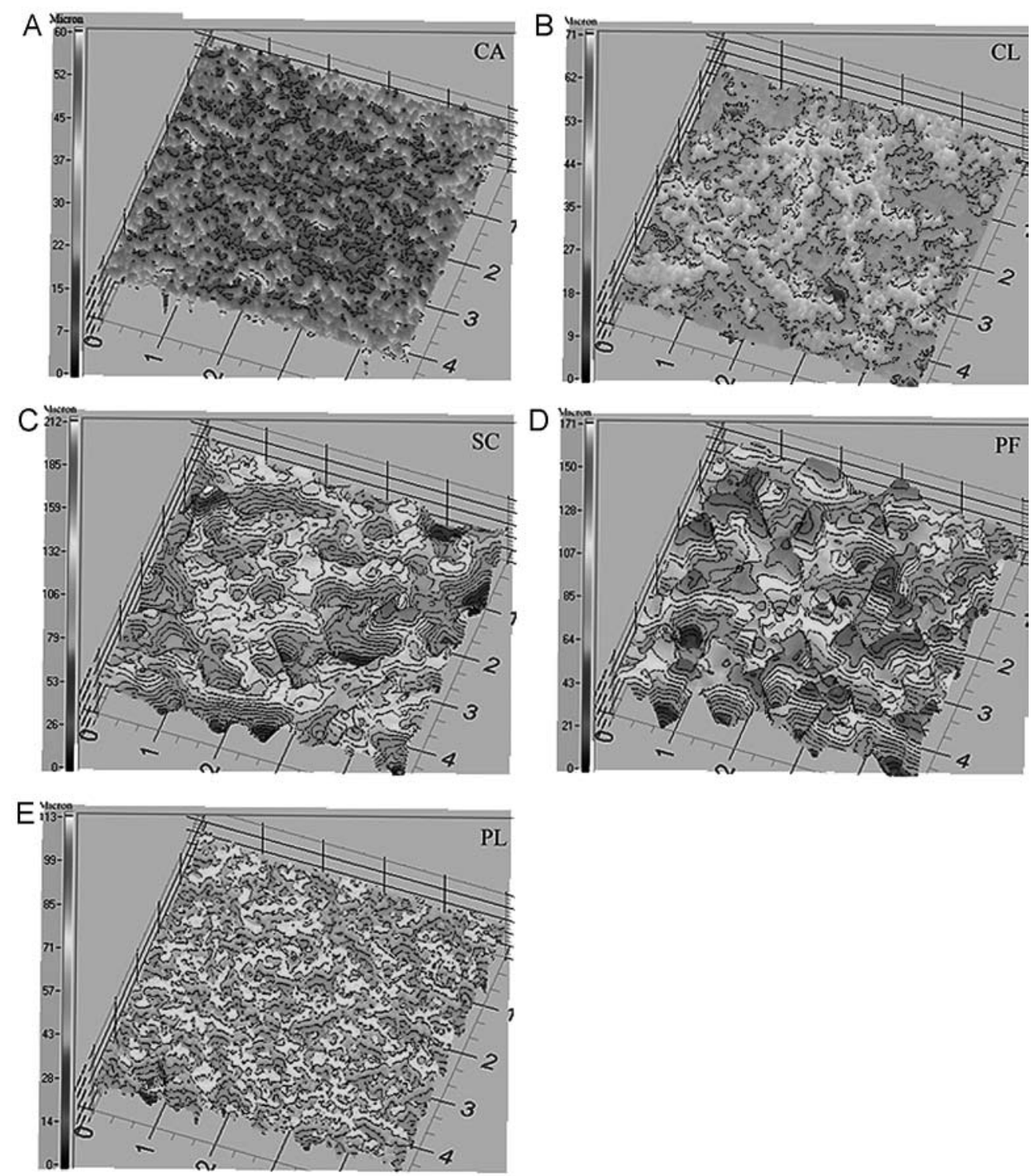

FIG. 1 - 3D image of the surfaces of the different lithotypes: A: Ançã limestone (CA); B: Lioz limestone (CL); C: San Cristobal stone (SC); D: Escúzar stone (PF); and E: Lecce stone (PL), obtained under optical surface roughness. 
TABLE 2 - Average chemical analysis in weight percent of the five lithotypes

\begin{tabular}{lccccc}
\hline & \multicolumn{5}{c}{ Lithotypes } \\
\cline { 2 - 6 } & $\mathrm{CA}$ & $\mathrm{CL}$ & $\mathrm{SC}$ & $\mathrm{PF}$ & $\mathrm{PL}$ \\
\hline $\mathrm{SiO}_{2}$ & 3.12 & 2.15 & 38.45 & 1.19 & 0.33 \\
$\mathrm{Al}_{2} \mathrm{O}_{3}$ & 0.41 & 0.12 & 0.20 & 0.252 & 0.79 \\
$\mathrm{Fe}_{2} \mathrm{O}_{3}$ & 0.12 & 0.11 & 0.41 & 0.16 & 0.28 \\
$\mathrm{MgO}$ & 0.40 & 0.25 & 0.10 & 0.32 & 0.45 \\
$\mathrm{CaO}$ & 53.47 & 0.15 & 33.72 & 53.39 & 55.23 \\
$\mathrm{Na}_{2} \mathrm{O}$ & 0.15 & 0.22 & 0.12 & 0.29 & 0.29 \\
$\mathrm{~K}_{2} \mathrm{O}$ & 0.13 & 0.00 & 0.05 & 0.08 & 0.13 \\
$\mathrm{MnO}$ & 0.00 & 42.90 & 24.59 & 0.02 & 0.00 \\
$\mathrm{LOI}^{*}$ & 42.06 & & 42.89 & 41.55 \\
\hline
\end{tabular}

* LOI: loss on ignition.

\section{Quantification of phototrophic growth on the limestone samples}

For the assessment of photosynthetic biomass developed on the inoculated stone samples, two different methods of chlorophyll a estimation were applied since the amount of chlorophyll is indicative of the amount of phototrophic microorganisms grown in the stone samples.

Photosynthetic biomass estimated by the chlorophyll extraction technique (in vitro) revealed a great increase of photosynthetic biomass during the incubation time for the PF lithotype (Fig. 2), indicating a successful colonisation. For the less porous lithotype $(\mathrm{CL})$, the amount of chlorophyll $a$ inoculated on the stone surface remained constant during 60 days of experimentation. After this incubation-period, a very slight increase was observed. CA and PL stone exhibited an abrupt increase of photosynthetic biomass during the first 30 days of incubation, decreasing progressively after this incubation-period. This observation is in accordance with macroscopic inspection, as the surfaces of CA and PL have become brown.

Regarding the in vivo chlorophyll a fluorescence measured on the surface of the stone samples immediately after inoculation and after 90 days of incubation, the emission spectra showed the typical chlorophyll a fluorescence peak at $684 \mathrm{~nm}$ (Fig. 3A). High fluorescence intensities represent a high quantity of photosynthetic biomass on the surface of the stone samples. After 90 days, high fluorescence intensities were obtained for the lithotypes presenting visible biofilms formed on the surface of the stone samples. These results were obtained on the lithotypes with fine grained textures, CA and PL (Fig. 3B). The fluorescence intensities for the very-fine grained lithotype (CL) remained almost the same as recorded immediately after inoculation and after 90 days of incubation. During the second month very low fluorescence intensity was detected.

In general, the chlorophyll fluorescence intensities increased during the first 30 days of incubation in all cases and after 60 days of experimentation, with the exception of the SC stone (Fig. 3B). The intensity of chlorophyll a fluorescence of this mediumgrained lithotype decreased over the incubation time (Fig. 3B).

The results obtained using the in vivo chlorophyll a fluorescence were different from those obtained with the in vitro chlorophyll a technique (Fig. 2), especially for SC stone. For this lithotype there was a significant decrease in the fluorescence intensities, whereas the amount of chlorophyll $a$ tended to increase. This apparent contradiction is related to the inherent feature of these techniques: the quantity of chlorophyll using the extraction technique obtained a complete amount of this pigment, while in vivo chlorophyll fluorescence only detects the photosynthetic biomass on the surfaces.

The results of phototrophic growth obtained after 30, 60 and 90 days are shown in Fig. 4. It shows the clear independent behaviour between chlorophyll a fluorescence and the amount of chlorophyll a obtained for SC and PF samples. PL

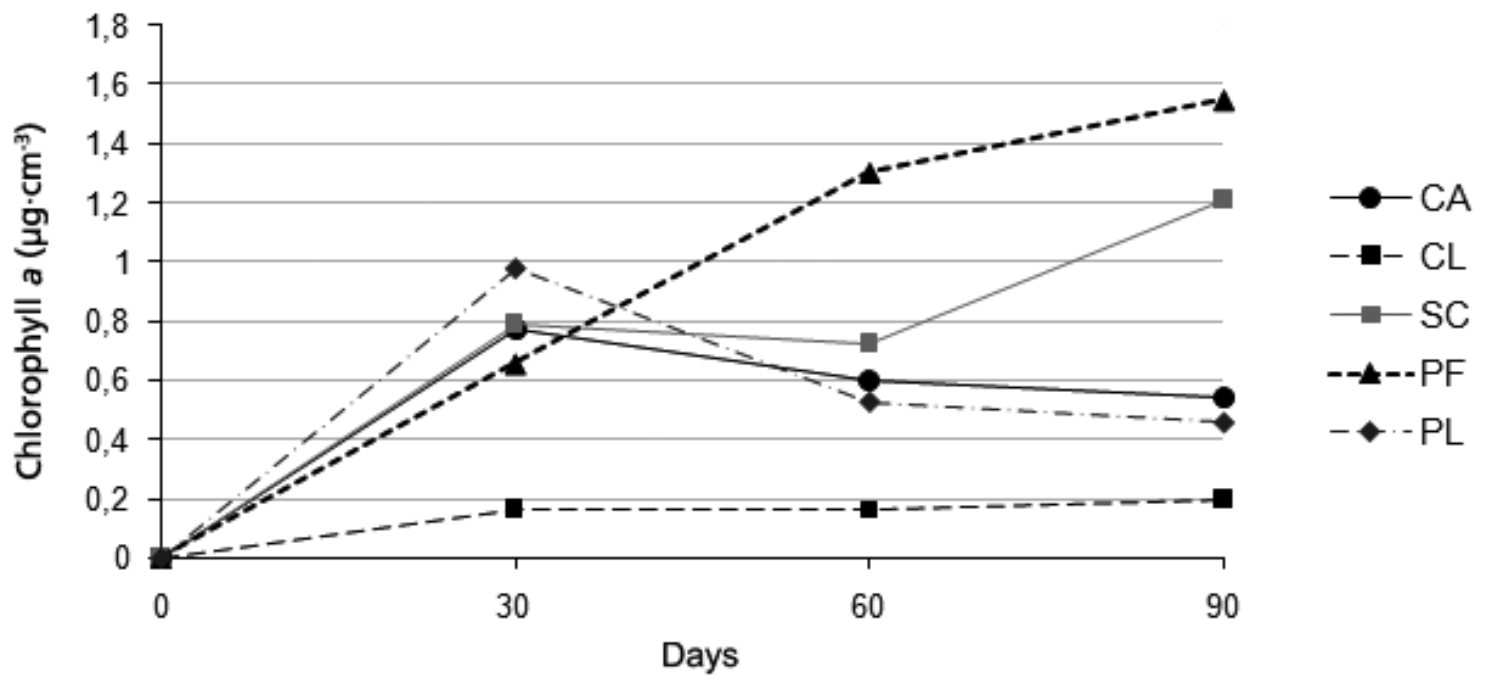

FIG. 2 - Maximum amount values of chlorophyll a measured by the chlorophyll extraction technique after 30, 60 and 90 days of incubation. 
A

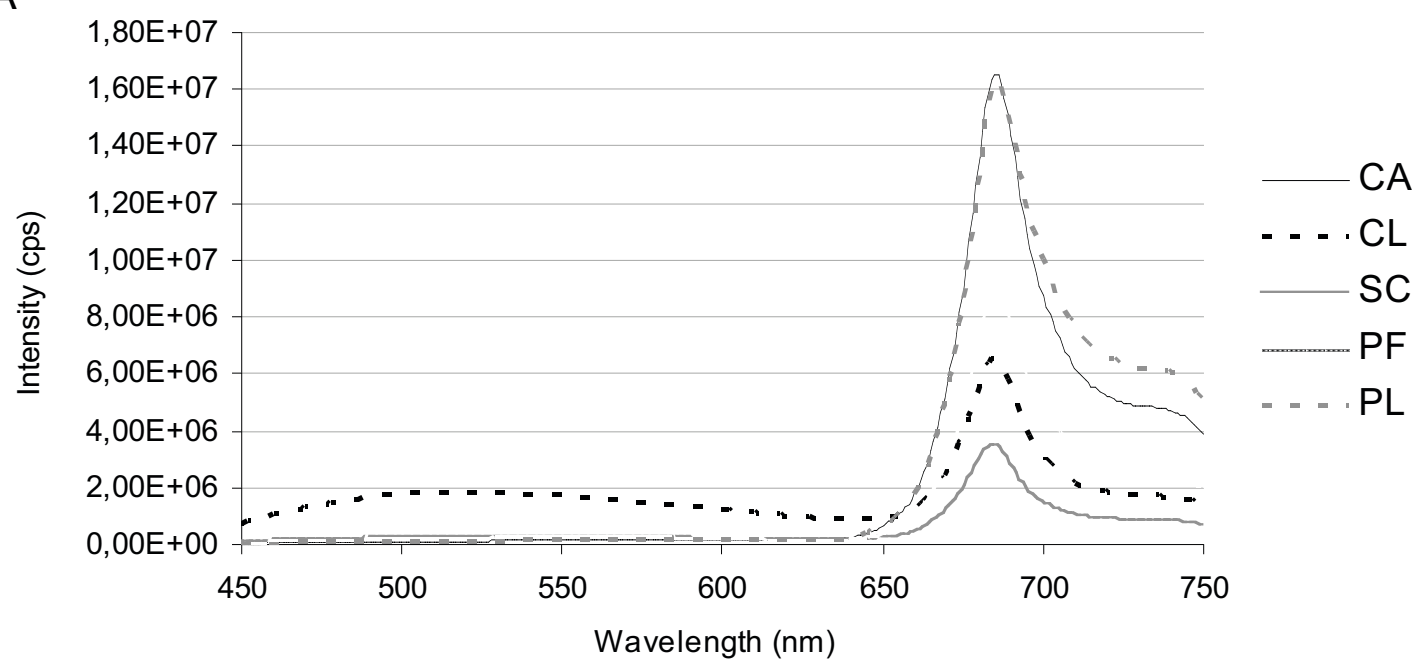

B

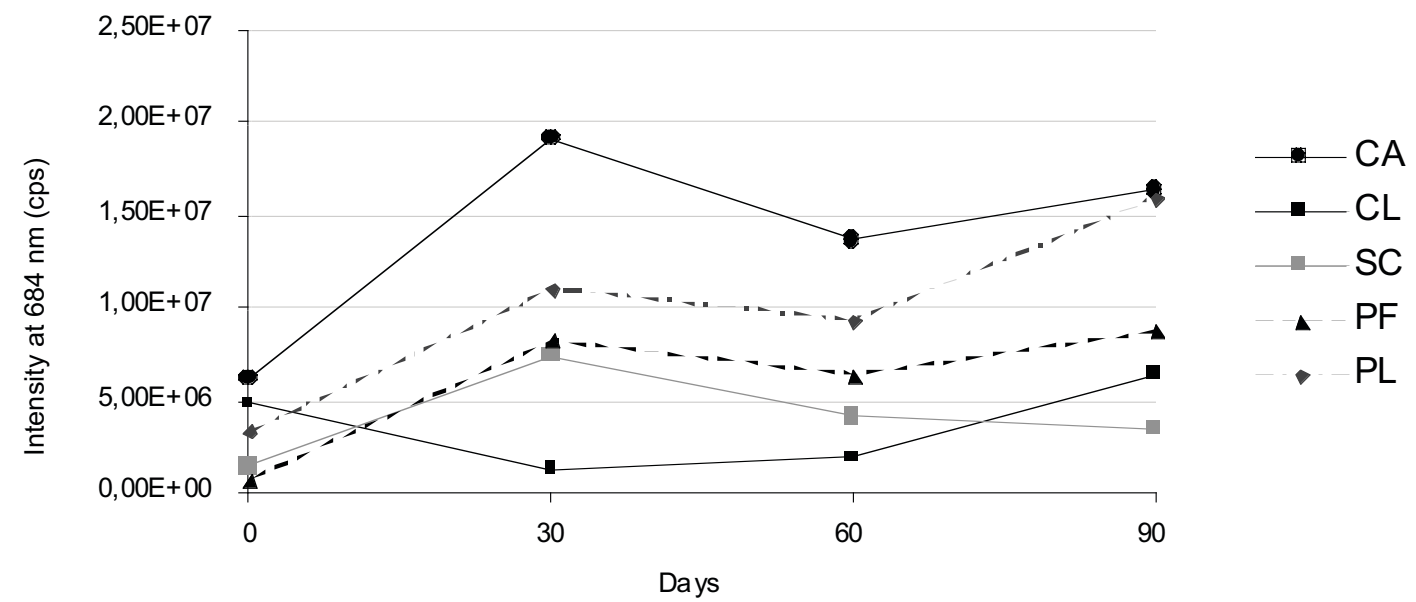

FIG. 3 - Intensities of chlorophyll a fluorescence obtained for each lithotype (excitation wavelength: $430 \mathrm{~nm}$ ). A: Chlorophyll fluorescence spectra measured after 90 days of incubation. Each lithotype spectrum is an average of 15 spectra. B: Intensity values of chlorophyll a fluorescence at $684 \mathrm{~nm}$ measured immediately after inoculation ( 0 days), 30, 60 and 90 days of incubation. Each point corresponds to the mean value of an average of 15 measurements.

showed a highly correlation between the two parameters of chlorophyll a quantification in the course of the incubation time (Fig. 4E).

\section{Principal component analysis}

A principal component analysis (PCA) was performed in order to establish the structure of the variable dependence. This involves the identification of relationships between variables and in assigning a petrophysical/photosynthetic biomass meaning of each factor. Based on PCA results (Fig. 5), two principal components (PC) were extracted which account for $91.47 \%$ of the total variance. PC1 accounts for $65.32 \%$ of total variance and is mostly linked to porosity, permeability, capillarity, roughness and the amount of chlorophyll a obtained after 90 days of incubation. The amount of chlorophyll $a$ is substantially and linearly associated to the capillary coefficient and roughness parameters, and less associated to the open porosity and water vapour permeability variables. PC2 accounts for $26.15 \%$ of total variance and is associated with the intensity of chlorophyll fluorescence obtained after 90 days. PC1 variables were not linearly related to the intensity of chlorophyll fluorescence obtained after 90 days since they were positioned perpendicularly.
The results of the statistical analysis, derived from the correlation matrix, revealed a positive experimental correlation between the amount of chlorophyll $a$ and the capillary coefficient (correlation $>0.94$ ) and roughness (correlation $>0.68$ ) of the five lithotypes. This indicates that the establishment and development of phototrophic colonisation were mostly influenced by the capillary coefficient and surface roughness ( $R a$ and $R z$ ).

\section{DISCUSSION}

In this study, two methods for estimation of photosynthetic biomass under laboratory conditions were performed in order to establish the influence of some intrinsic properties on the bioreceptivity of five different limestones largely used in European countries from the Mediterranean Basin.

San Cristobal and Escúzar lithotypes are biocalcarenites of medium coarse-grain, which displayed the highest values of chlorophyll a estimated by the chlorophyll a extraction technique. Given their capillary coefficient, open porosity, water vapour permeability, degree of cementation, and carbonate composition, the San Cristobal and Escúzar stones revealed that they are prone 


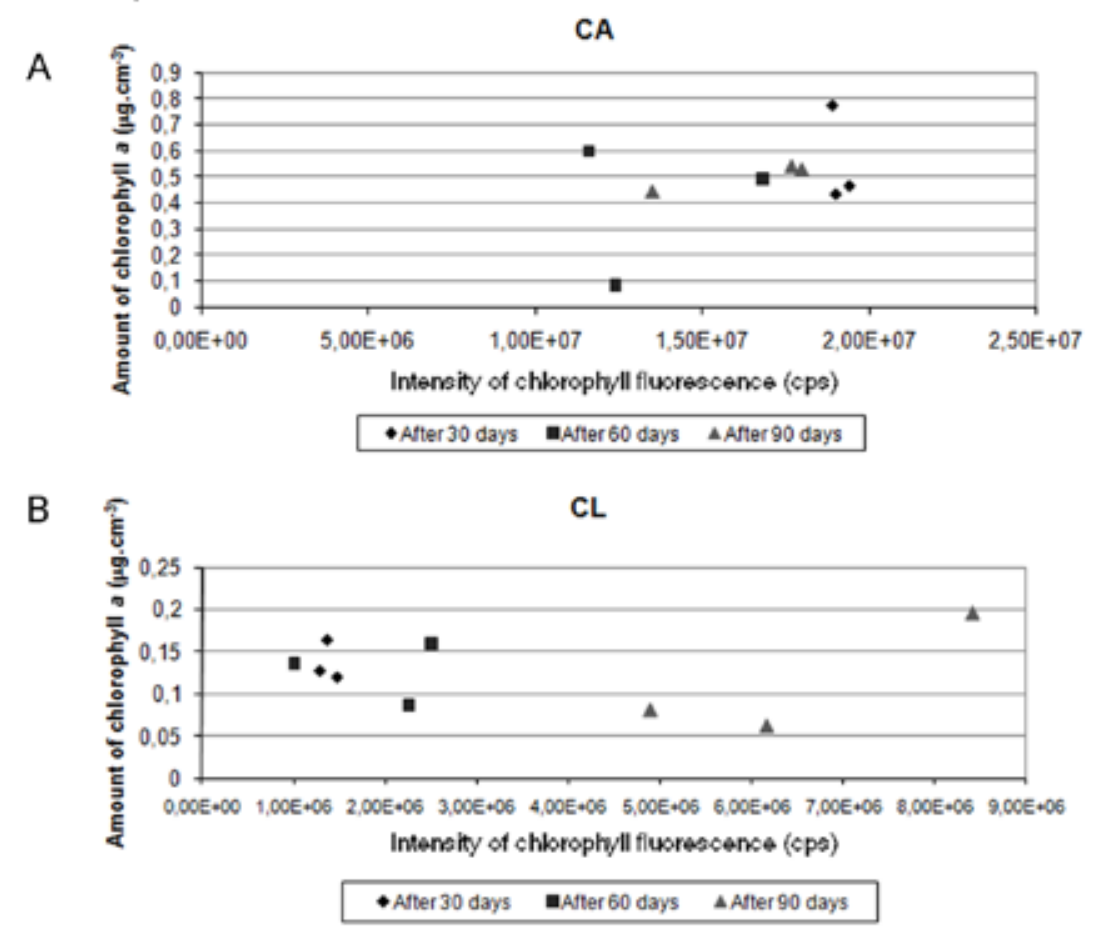

C

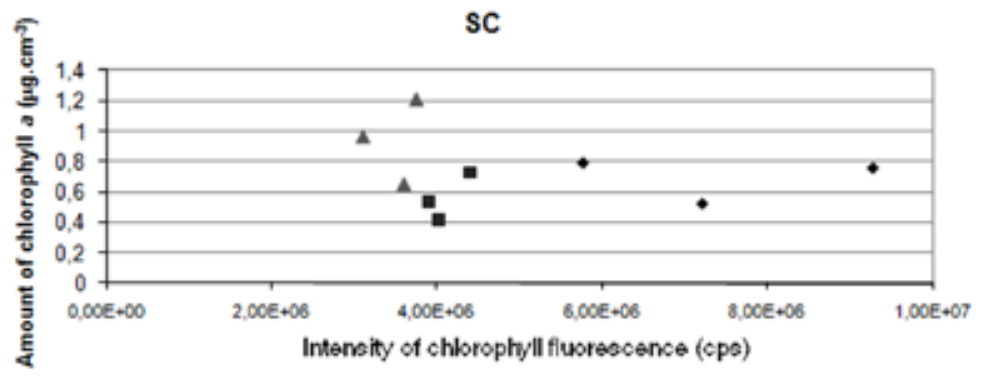

-After 30 days =Atter 60 days $\triangle$ After 90 days

D

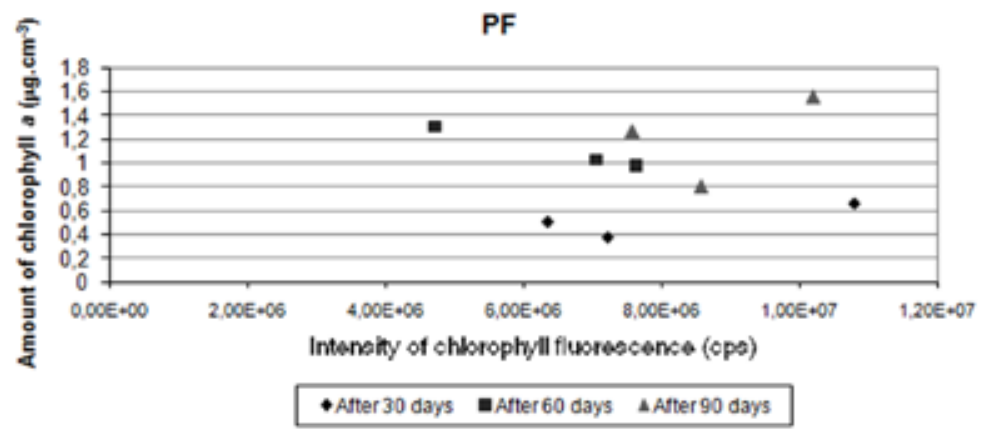

E

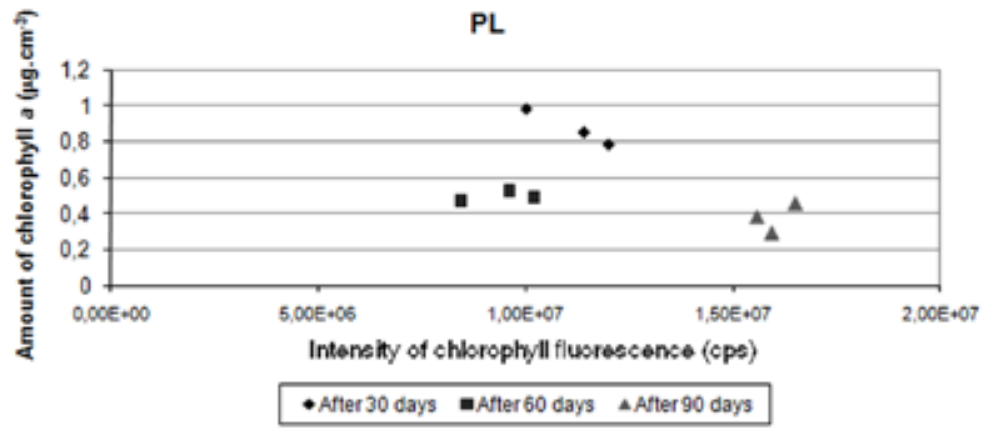

FIG. 4 - Relations between chlorophyll fluorescence and amount of chlorophyll a, obtained by the in vivo and in vitro chlorophyll a techniques, respectively. 
Projection of the variables on the factor-plane $(1 \times 2)$

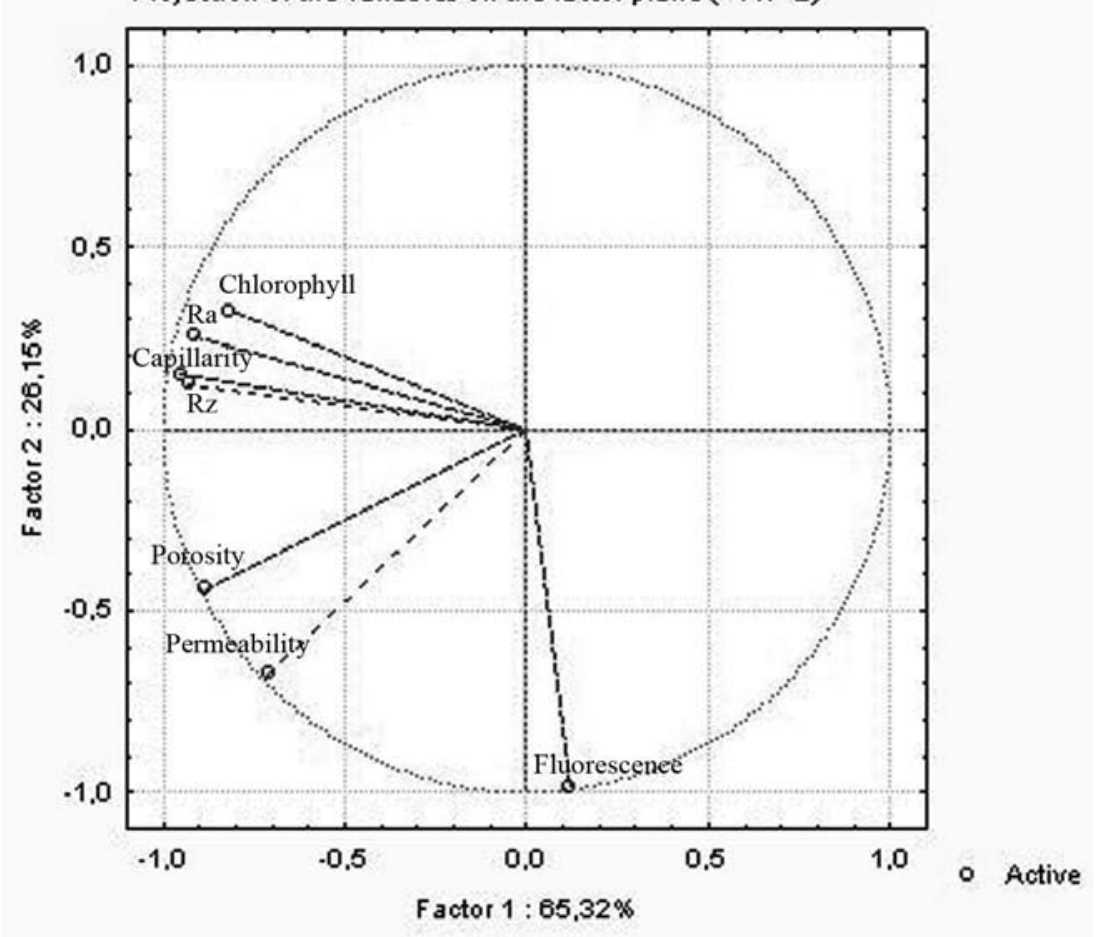

FIG. 5 - Correlation among the variables capillary coefficient (Capillarity), surface roughness (Ra and Rz), open porosity (Porosity), water vapour permeability (Permeability), amount of chlorophyll a (Chlorophyll) and chlorophyll a fluorescence (Fluorescence), and the factors (components).

to phototrophic colonisation. The very-fine grained lithotype (Lioz limestone) together with its very low water vapour permeability and open porosity values limited the growth of photosynthetic microorganisms on this stone surface. However, both chlorophyll a quantification techniques revealed a very light increase of photosynthetic biomass after 60 days of incubation under laboratory conditions, indicating that a phototrophic colonisation would progressively increase. According to Tomaselli et al. (2002), high water-permeability of coarse-grained stones favours a rapid and temporary biological colonisation, while permanent microbial establishment occurs in fine-grained stones that can hold moisture for a longer time, as is the case of Lioz limestone.

The progressive decrease of chlorophyll a obtained for the Ançã limestone and the Lecce stone in combination with the biofilms brownish colour point to relatively high concentrations of pheophytine degradation products and thus a low viability of the population considered or the cessation of colonisation (Stal et al., 1984).

In what concerns the relationship between phototrophic microorganisms and the intrinsic properties of the stone materials, the present case study indicates that the preferential colonisation of the five lithotypes seems to be primarily dependent on the capillary coefficient and roughness, rather than on open porosity and permeability. The extent of microbial colonisation appears to increase as the surface roughness increases. This is because shear forces are diminished, and total surface area is higher on rougher surfaces (Morton et al., 1998). The obtained results are in accordance with the results achieved by Guillitte and Dreesen (1995), Tiano et al. (1995) and Tomaselli et al. (2000).

The intrinsic properties assessed in this work were important parameters for the adherence and establishment of microbial communities on the stone surfaces. Adhesion of the microorganisms is regulated biologically by the microbial cell structure and their surface charge. It is physically controlled by the stone surface, which partially determines the availability of water, nutrients, niche possibilities, and thus the survivability of the microbes (Koestler et al., 1996). Yet clearly, microbial colonisation of stone monuments is dependent on the availability of water allowing microorganisms to form biofilms on the stone surfaces. Rain or inundation penetration, water vapour condensation and drying by shrinkage are some examples of water availability on buildings. These water and moisture availability lead to microorganisms growth and spreading on and within the material causing significant damage.

Considering the chlorophyll a quantification methods used in this study, the amount of chlorophyll a estimated by the extraction technique allowed quantifying the complete amount of photosynthetic biomass growing on and within the stone samples, whereas the in vivo chlorophyll a fluorescence only estimated photosynthetic biomass developing on the stone surfaces. Nevertheless, the results obtained from both techniques allowed to corroborate that phototrophic colonisation occurred mainly within the stone samples (endolithic growth) of San Cristobal and Escúzar stones. It showed that the good correlation between both chlorophyll a quantification methods was only achieved for epilithic growth. Whenever endolithic growth was established those correlations failed. Nevertheless, little if any attempt appears to have been made to the study of endolithic growth under laboratory conditions. Further work will focus on the endolithic growth occurred in the lithotypes.

In conclusion, the chlorophyll concentrations can be used as a parameter for the detection of phototrophic organisms on stone materials and the assessment of biodeterioration parameters. However, the methods of in vitro quantification of photosynthetic biomass are disruptive in nature, due to the extraction procedures; therefore, they are not applicable for the monitoring of 
photosynthetic growth on stone monuments since it requires successive sampling procedures. This problem is overcome by the in vivo chlorophyll a technique, which revealed to be an important tool for the detection of epilithic photosynthetic colonisations. Moreover, this method showed high sensitivity for the detection of very low concentrations of chlorophyll a allowing the detection of photosynthetic microorganisms at an early growth stage on the stone surfaces. Unfortunately, endolithic growth is not detected by this technique, which represents a major obstacle when an integral study of the stone phototrophic ecosystem is needed.

\section{Acknowledgements}

This work has been performed in the framework of the project 2007PT0041 (CSIC-FCT). This study has been financed by the Ministério da Ciência, Tecnologia e Ensino Superior, Portugal, with a doctoral grant (SFRH/BD/21481/2005) and partially financed by CEPGIST FCT subproject DECASTONE. This work also received support from Programa de Financiamento Plurianual de Unidades de Investigação da FCT, financed by European Union FEDER and national budget of the Portuguese Republic. This is also a paper from the project CONSOLIDER CSD2007-00058.

\section{REFERENCES}

ASTM E96/E96M - 05 (2005). Standard Test Methods for Water Vapour Transmission of Materials, ASTM.

Bellinzoni A.M., Caneva G., Ricci S. (2003). Ecological trends in travertine colonisation by pioneer algae and plant communities. Int. Biodeter. Biodegr., 51: 203-210.

Burnison B.K. (1980). Modified Dimethyl Sulfoxide (DMSO) extraction for chlorophyll analysis of phytoplankton. Can. J. Fish. Aquat. Sci., 37: 729-733.

Cecchi G., Pantani L., Raimondi V., Tomaselli L., Lamenti G., Tiano P., Chiari R. (2000). Fluorescence lidar technique for remote sensing of stone monuments. J. Cult. Herit., 1: 29-36.

Chilingar G.V., Bissel H.J., Fairbridge R.W. (1967). Carbonate Rocks. Physical and Chemical Aspects. Developments in Sedimentology 9B. Elsevier, New York.

Costerton J.W., Lewandowski Z., Caldwell D.E., Korber D.R., Lappin-Scott H.M. (1995). Microbial biofilms. Ann. Rev. Microbiol., 49: 711-745.

EN 1925:1999 (1999). Natural Stone Test Methods - Determination of Water Absorption Coefficient by Capillarity. European Committee for Standardization (CEN), Belgian.

EN 1936:1999 (1999). Natural Stone Test Method - Determination of Real Density and Apparent Density, and of Total and Open Porosity. European Committee for Standardization (CEN), Belgian.

Gorbushina A.A. (2007). Life on the rocks. Environ. Microbiol., 9: $1613-1631$.

Guillitte O. (1995). Bioreceptivity: a new concept for building ecology studies. Sci. Total Environ., 167: 215-220.

Guillitte O., Dreesen R. (1995). Laboratory chamber studies and petrographical analysis as bioreceptivity assessment tools of building materials. Sci. Total Environ., 167: 365-74.

Koestler R., Warscheid T., Nieto F. (1996). Biodeterioration: Risk factors and their management. In: Baer N.S., Snethlage R.,
Eds, Saving Our Architectural Heritage - The Conservation of Historic Stone Structures. John Wiley \& Sons, pp. 25-35.

Lorenzen C.J. (1967). Determination of chlorophyll and pheopigments: spectrophotometric equations. Limnol. Oceanogr., 12: 343-346.

Miller A., Dionisio A., Macedo M.F. (2006). Primary bioreceptivity: A comparative study of different Portuguese lithotypes. Int. Biodeter. Biodegr., 57: 136-142.

Miller A.Z., Laiz L., Dionísio A., Macedo M.F., Saiz-Jimenez C. (2009). Growth of phototrophic biofilms from limestone monuments under laboratory conditions. Int. Biodeterior. Biodegrad, 63: 860-867

Miller A.Z., Leal N., Laiz L., Rogerio-Candelera M.A., Gonzalez J.M., Silva R.J.C., Dionísio A., Macedo M.F., Saiz-Jimenez C. (2010). Primary bioreceptivity of limestones used in Southern Europe monuments. In: Gomez-Heras M., Ed., Limestone in the Built Environment: Present Day Challenges for the Preservation of the Past. Geological Society, London (in press).

Morton L.H.G., Greenway D.L.A., Gaylarde C.C., Surman S.B. (1998). Consideration of some implications of the resistance of biofilms to biocides. Int. Biodeter. Biodegr., 41: 247-259.

Normal 21/85. (1985). Permeabilità al vapor d'acqua. Commissione Normal, CNR/ICR, Roma.

Prakash B., Veeregowda B.M., Krishnappa G. (2003). Biofilms: A survival strategy of bacteria. Curr. Sci., 85: 1299-1307.

Prieto B., Silva B. (2005). Estimation of the potential bioreceptivity of granitic rocks from their intrinsic properties. Int. Biodeter. Biodegr., 56: 206-215.

Rodriguez-Navarro C., Sebastian E. (1996). Role of particulate matter from vehicle exhaust on porous building stones (limestone) sulfation. Sci. Total Environ., 187: 79-91.

Shirakawa M.A., Beech I.B., Tapper R., Cincotto M.A., Gambale W. (2003). The development of a method to evaluate bioreceptivity of indoor mortar plastering to fungal growth. Int. Biodeter. Biodegr., 51: 83-92.

Shoaf W.T., Lium B.W. (1976). Improved extraction of chlorophyll $a$ and $b$ from algae using dimethyl sulfoxide. Limnol. Oceanogr., 21: 926-928.

Stal L.J., Gemerden H., Krumbein W.E. (1984). The simultaneous assay of chlorophyll and bacteriochlorophyll in natural microbial communities. J. Microbiol. Meth., 2: 295-306.

Talling J.F., Driver D. (1963). Some problems in the estimation of chlorophyll a in phytoplankton. In: Doty M.S., Ed., Conference of Primary Productivity Measurement, Marine and Freshwater. Atomic Energy Comm., pp. 142-146.

Tiano P., Accolla P., Tomaselli L. (1995). Phototrophic biodeteriogens on lithoid surfaces: an ecological study. Microb. Ecol., 29: 299-309.

Tomaselli L., Lamenti G., Bosco M., Tiano P. (2000). Biodiversity of photosynthetic micro-organisms dwelling on stone monuments. Int. Biodeter. Biodegr., 46: 251-258.

Tomaselli L., Lamenti G., Tiano P. (2002). Chlorophyll fluorescence for evaluating biocide treatments against phototrophic biodeteriogens. Ann. Microbiol., 52: 197-206.

Vollenweider R., Talling J., Westlake D., Eds (1974). A Manual on Methods for Measuring Primary Production in Aquatic Environments. Blackwell, Oxford. 
